\title{
What can we learn on rodent fearfulness/anxiety from the genetically heterogeneous NIH-HS rat stock?
}

\author{
Sira Díaz-Morán ${ }^{1 *}$, Esther Martínez-Membrives ${ }^{1}$, Regina López-Aumatell ${ }^{2}$, Toni Cañete ${ }^{1}$, \\ Gloria Blázquez ${ }^{1}$, Marta Palencia ${ }^{1}$, Carme Mont-Cardona ${ }^{1,2}$, Celio Estanislau ${ }^{3}$, Adolf Tobeña ${ }^{1}$, \\ Alberto Fernández-Teruel ${ }^{*}$
}

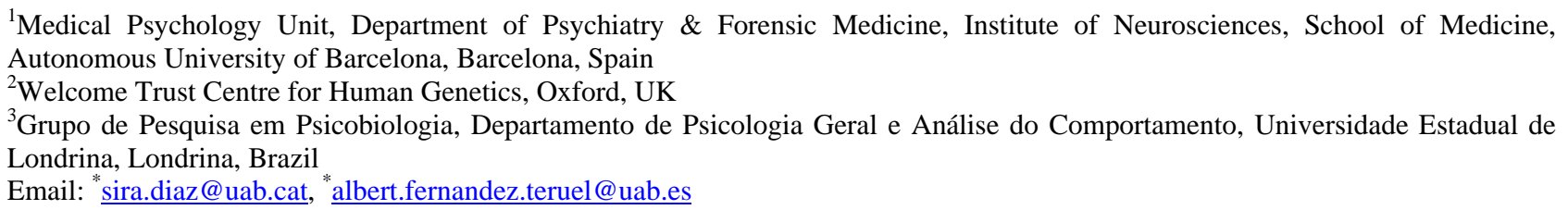

Received 30 January 2013; revised 2 March 2013; accepted 11 March 2013

Copyright (C 2013 Sira Díaz-Morán et al. This is an open access article distributed under the Creative Commons Attribution License, which permits unrestricted use, distribution, and reproduction in any medium, provided the original work is properly cited.

\begin{abstract}
The "National Institutes of Health" genetically heterogeneous (NIH-HS) rat stock was created in the 1980s through an eight-way cross of as much as possible separate inbred rat strains (i.e. the $M R / N$, WN/N, WKY/N, M520/N, F344/N, ACI/N, BN/SsN and $B U F / N$ strains) which were readily available at that time. Hansen and Spuhler [1] developed a more naturalistic, genetically heterogeneous rat stock with the aim of optimizing the distribution of genotypic frequencies and recombination and under the hypothesis that the NIH-HS stock could yield a broad-range distribution of responses (broader than commonly used laboratory rat strains) to experimental conditions, and thus serve as a base population for selection studies. Along the last decade, in a series of studies we have phenotypically characterized the NIH-HS rat stock (a colony exists at our laboratory since 2004) for their anxiety/fearfulness profiles (using a battery of both unconditioned and conditioned tests/tasks), as well as regarding their stress-induced hormonal responses, coping style under inescapable stress and spatial learning ability. We have also compared the phenotypic profiles of NIH-HS rats with those of the low anxious RHA-I and the high anxious RLA-I rat strains. The NIH-HS rat stock is, as a population, a rather anxious type of rat, with predominantly reactive/passive coping style in unlearned and learned anxiety/fear tests, and elevated stress hormone responses (as well as enhanced "depressive” symptoms in the forced swimming test). Genetic
\end{abstract}

${ }^{*}$ Corresponding authors. studies currently under way have thus far revealed that the genetically heterogeneous NIH-HS rat stock constitutes a unique tool for fine mapping of QTL (for multiple behavioural and biological complex traits) to megabase resolution levels, thus enabling candidate gene identification. We give some examples of this in the present paper, while also highlighting that microarray gene expression studies reveal that HPA-axis- and prolactin-related genes (among others) in the amygdala appear to be related with (or associated to) the coping style and anxiety/fearfulness responses of NIH-HS rats.

Keywords: Anxiety; Fearfulness; Stress Hormones; HPA Axis Responses; Forced Swimming Test; Genetically Heterogeneous NIH-HS Stock; RHA-I/RLA-I Rats

\section{INTRODUCTION}

About three decades ago Hansen and Spuhler raised the issue that most commonly used outbred laboratory rat stocks could have a rather narrow genetic ancestry [1]. These authors noticed that many (perhaps the majority) of available outbred lines appeared to trace their ancestry, at least in part, to a stock that was maintained at the Wistar Institute in Philadelphia from a period before First World War to the 1950s. This Wistar colony was, in turn, derived and established in Europe from a small group of rats just around 1900 (for review see [1]). The origins of Sprague-Dawley and Long-Evans stocks were also based on a very small number of breeders, as each of them derived from a single mating between (pre- 
sumably) a Wistar female and males from different sources, including a wild-type one. It is likely that these two outbred stocks were subject of significant inbreeding and selection in the initial generations (for references see [1]).

Thus, with the purpose of overcoming the problem of too narrow and shared genetic ancestry in the available outbred rat stocks, Hansen and Spuhler [1] developed a more naturalistic, genetically heterogeneous rat stock which could hypothetically yield a broad-range distribution of responses to experimental conditions and could serve as a base population for selection studies. So, with the goal of optimizing the distribution of genotypic frequencies and recombination within the laboratory rat population, the "National Institutes of Health-N/NIHGenetically Heterogeneous Rat Stock" (hereafter NIHHS rats) was formed through an eight-way cross of as much as possible separate inbred strains which were readily available. These eight parental strains were: the $\mathrm{MR} / \mathrm{N}, \mathrm{WN} / \mathrm{N}$ and $\mathrm{WKY} / \mathrm{N}$ (these three strains trace their ancestry to the original Wistar stock); the M520/N and F344/N (both established in the 1920s, but of unknown origin); the ACI/N (hybrid between the August and Copenhagen strains), the BN/SsN (derived from a colour mutant from a stock of wild rats kept at the Wistar Institute) and the BUF/N strain [1,2].

The phenotypes showed by these NIH-HS rats in up to 16 ethanol-related traits lend initial support to the effectiveness of the program, as for all traits except one the values of the heterogeneous stock were within the high and low values of the eight founder inbred strains [1,2]. Successful selection studies have also been carried out, departing from the NIH-HS rat stock, by breeding divergent lines of rats on the basis of their extreme values in, for instance, sensitivity to acute ethanol [3], aerobic running capacity $[4,5]$ and serotonin-1A receptor sensitivity [6].

\section{PROFILES AND DIMENSIONS OF FEARFULNESS/ANXIETY IN NIH-HS RATS}

\subsection{NIH-HS Rats as High Anxious Rodents: A Multi-Test Approach and Comparisons with Roman Fearful and Nonfearful Rat Strains}

By the time we started to work with the genetically heterogeneous rat stock in 2005 (breeding pairs to build the colony at our laboratory were kindly provided by Dr. Eva Redei, Northwestern University, Chicago, USA), these NIH-HS rats had not been characterized in regard to novelty-related exploration and fearfulness (anxietyrelated) responses. This is why, within the context of a wider study on the genetic basis of anxiety/fearfulness (i.e. a QTL fine mapping study within the European "EURA Tools" consortium; see [7]), we have carried out a battery of behavioural tests on those heterogeneous rats (the particular tests could vary across the different studies performed; see below) with the aim of providing behavioral profiles and studying the factorial/dimensional structure of the different behavioral measures in both sexes. Thus, with this goal in mind, in different studies we have characterized several and separate large samples (from $n>100$ to $n>1400$ depending on the study) of $\mathrm{NIH}-\mathrm{HS}$ rats in a series of fearfulness-related phenotypes, including novelty-induced exploratory activity, unlearned and learned fear/anxiety responses (see [8-13]). The multitest battery used comprises unconditioned tests of novelty-induced and habituated exploratory activity, the light/dark box, the open field and the "elevated zeromaze” (ZM) tests for unconditioned anxiety (e.g. see evidence for the validity of these tests in [14-16]), and the baseline acoustic startle test (e.g. $[17,18])$. As conditioned anxiety/fear tests, we have used the fear-potentiated startle (e.g. [19,20]), context-conditioned freezing (i.e. classical aversive/fear conditioning) and the acquisition of two-way active avoidance in a shuttle box (e.g. see evidence for the validity of this task in [21-27]).

The results added completely new and relevant phenotypic information of NIH-HS rats by revealing the position of these heterogeneous rats in regard to their defensive behavioral profiles when compared with two thoroughly studied inbred strains which show very divergent anxiety and fearful profiles as well as coping styles, i.e. the low anxious/low fearful RHA-I and the high anxious/high fearful RLA-I rat strains [8-29].

As a matter of fact, that series of studies have shown, for the first time, that:

(1) In measures of novel-cage (i.e. open-field-like) activity, novelty-induced self-grooming responses, "latency to the first entry into an open section”, spontaneous “exploratory crossings between compartments" (during the period of familiarization to the shuttle box), "number of entries into open sections" and "time spent in open sections" of the "elevated zero-maze" (ZM) test of anxiety, the mean values of the NHS-HS rat stock resemble more the scores of RLA-I rats (as an example see Table 1(a)) which, in turn, are more anxious/fearful than the RHA-I strain according to those behavioural parameters (see [8-11,28,29]).

(2) In the acoustic startle paradigm, in which the inbred Roman strains also show extremely divergent scores (the RLA-I strain displaying much higher levels of baseline and fear-potentiated startle than RHA-I rats; see [9, $10,20])$, NIH-HS rats fall in between both Roman rat strains regarding both the baseline startle and the fearpotentiated startle response $[9,10]$.

(3) The level of avoidance acquisition of NIH-HS rats 
(between 3 - 7 avoidances in a single 40 - 50-trial shuttle box training session, depending on the particular study; e.g. $[8-13,29,30])$ is also very close to that of RLA-I rats (usually 0 - 3 avoidances in a 40-trial shuttle box training session, depending on the particular study), and much lower than the scores of RHA-I rats, which usually perform $\geq 25$ avoidances in a 40-trial session (as an example see Table 1(b)). It might also be informative, in regard to the relative position of NIH-HS rats with respect to other strains/stocks in that task, that Sprague-Dawley rats - from the Autonomous University of Barcelona, UAB - have shown avoidance scores falling within a range of 10 - 16 avoidances in 40 trials in many studies carried out over the last 25 years in our lab at the UAB (see references to these works in López-Aumatell et al. [8]).

(4) The levels of context-conditioned freezing (i.e. classically conditioned fear) displayed by NIH-HS rats during the initial stages of the shuttle box training session (when no rat has still made any avoidance response) are also more similar to the freezing levels shown by the high anxious RLA-I rats (around 170 - $250 \mathrm{~s}$ in a 5-min period, depending on the study; as an example see Table 1(b) and references below) than to those displayed by RHA-I rats ( $\leq 40 \mathrm{~s}$ in a 5 -min period; see $[9,11,13,29]$ ).

(5) By comparing subgroups of NIH-HS rats showing extremely low or high values (1 standard deviation below or above the mean) of some relevant variables we have found that some (extreme) unlearned anxiety behaviors are predictive of scores in learned anxiety-related responses (this issue will be discussed in the next section; see $[10,11,13])$.

Thus, following Blanchards' conceptualization of rats' defensive behaviors [31,32] and their definition of defensive distance, from a qualitative viewpoint the NIHHS rats can be seen-very much as the RLA-I rat strain - as prone to freeze (rather than to flee, as the RHA-I strain does), when the defensive distance [31,32] is very short and the defensive direction (according to the concept of Gray and McNaughton, see [33,34]) is not clear because the situation involves a conflict between two incompatible goals (see Figure 1). The latter is the case of the initial stages of shuttle box avoidance acquisition, which involve anxiety because of the incompatible tendencies to (1) enter a dangerous situation (i.e. fleeing to the opposite compartment, where the rat has already re-

Table 1. Comparisons of unconditioned and conditioned anxiety responses among the Roman rat strains and the genetically heterogeneous NIH-HS rat stock. (a) Elevated zero-maze; (b) Two-way shuttle-box avoidance session.

(a)

\begin{tabular}{cccc}
\hline & RHA-I (n= 61) & RLA-I (n = 60) & NIH-HS (n = 60) \\
\hline Latency to open (s) & $64.5 \pm 11.6$ & $114.5 \pm 14.5$ (a) & $87.6 \pm 14.4$ (c) \\
Time (s) & $55.9 \pm 5.4$ & $40.9 \pm 5.7^{*}$ & $44.5 \pm 6.0$ \\
Entries (n) & $5.1 \pm 0.5$ & $2.9 \pm 0.4$ (b) & $3.4 \pm 0.4(\mathrm{~d})$ \\
SAP (n) & $11.2 \pm 0.6$ & $9.6 \pm 0.4$ & $7.1 \pm 0.4(\mathrm{c})$ \\
Head-dips (n) & $9.4 \pm 0.4$ & $5.7 \pm 0.8$ (b) & $4.6 \pm 0.5(\mathrm{~d})$ \\
Line crossings (n) & $20.5 \pm 1.6$ & $12.5 \pm 0.5$ (b) & $17.4 \pm 1.5(\mathrm{e})$ \\
\hline
\end{tabular}

(b)

\begin{tabular}{cccc}
\hline & RHA-I $(\mathbf{n}=\mathbf{1 0})$ & RLA-I (n= 12) & NIH-HS (n = 12) \\
\hline CET (n) & $11.2 \pm 1.2$ & $4.1 \pm 0.6$ & $5.4 \pm 0.6(\mathrm{~d})$ \\
Freezing (s) & $39.1 \pm 6.8$ & $170.6 \pm 9.2$ & $231.5 \pm 11.5(\mathrm{e})$ \\
ITC (n) & $107.0 \pm 12.5$ & $20.1 \pm 3.5$ & $16.6 \pm 2.1(\mathrm{~d})$ \\
Latency (s) & $6.5 \pm 0.5$ & $18.4 \pm 2.0$ & $12.0 \pm 1.0(\mathrm{e})$ \\
Avoidances (n) & $29.0 \pm 3.0$ & $3.3 \pm 1.4$ & $7.4 \pm 2.1(\mathrm{~d})$ \\
\hline
\end{tabular}

Means + SEM of behavioral measures of the 3 groups of rats are shown. (a) Elevated zero-maze test (5-min test). "Time”: time spent (s) in the open sections. "Entries": total number of entries in the open sections (n). "Head-dips": exploratory activity or head-dips below the level of the edge of the test (n). "SAP": stretched attend postures from the closed to the open sections (n). "Line-crossings": number of crossings across the eight sections of the maze (n); (b) Two-way shuttle-box avoidance session (50-trial session; 10-s conditioned stimulus-CS, light + tone plus 20 -s unconditioned stimulus-US, 0.7 mA scrambled footshock). "CET": total number of changes during the 4-min of free exploration of the shuttle box prior to the start of the 50-trial two-way avoidance training session. "Freezing": total time of freezing (s) during the first five 60-s inter-trial intervals of the two-way avoidance training session. "ITC": total number of inter-trial crossings (n). "Latency": mean response latency (since the moment in which the CS is presented) averaged for the 50 trials of the shuttle box avoidance session (s). "Avoidances": number of avoidances in the 50-trial shuttle box session (n). Detailed procedures of the elevated zero-maze test and the 50-trial two-way active avoidance session can be seen in reference [29]. (a), p < 0.05 vs. RHA-I group (Student's t-test for independent samples); (b), p < 0.001 vs. RHA-I (Student's t-test for independent samples); ${ }^{*} \mathrm{p}=0.057$; (c) $\mathrm{p}<0.05$ vs. Roman rat strains (Duncan’s test after significant one-way ANOVA); (d), $\mathrm{p}<$ 0.05 significant comparisons between NIH-HS and RLA-I vs. RHA-I (Duncan's tests after significant one-way ANOVA); (e), p < 0.05 significant comparisons between the three rat strains/stocks (Duncan's tests after significant one-way ANOVA). Results not previously published elsewhere. 


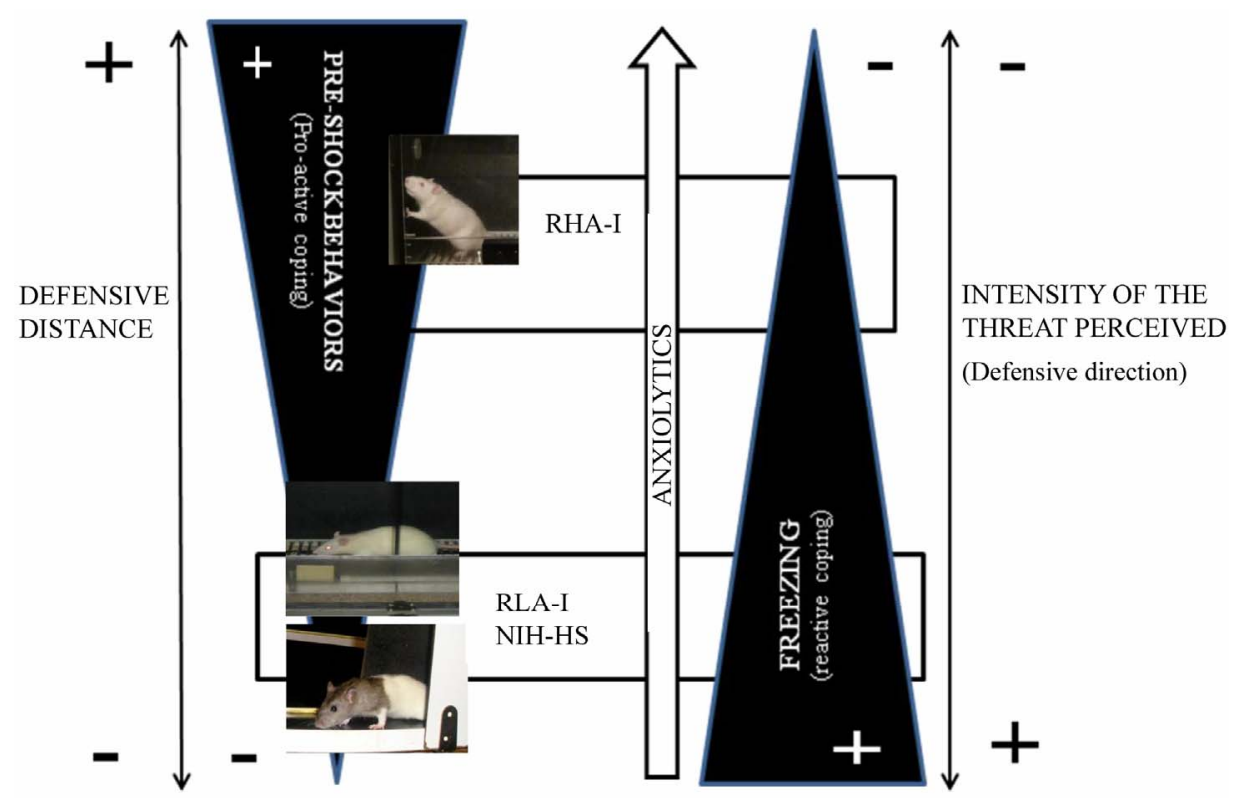

Figure 1. Relationships among defensive distance, intensity of perceived threat (defensive direction) and behavioural anxiety/fear (defensive) responses, showing the relative position of both Roman rat strains (RHA-I, low anxious/proactive copers, and RLA-I, high anxious/reactive copers, freezers) and the NIH-HS rat stock (passive copers, freezers) (the idea for the drawing was adapted from Blanchard et al.; Gray and McNaughton; McNaughton and Gray; López-Aumatell; references $[9,31,33,34])$.

ceived a shock-active escape or avoidance) or (2) to remain (i.e. to freeze-passive avoidance) in the present one, which is also threatening for the animal (as the rat also received shock in that one). Hence, at least at the beginning of the shuttle box two-way avoidance task the "defensive distance" is very short and the "defensive direction" is unclear for the animal (following the above definitions, see [31-34]), so that NIH-HS (as well as RLA-I) rats show a strong tendency to freeze (Figure 1; e.g. $[11,13,29])$. As the training session advances, a route (and a directed behaviour) to escape becomes progressively evident for the rats (i.e. crossing to the opposite compartment of the shuttle box) and escape behavior is established. Moreover, in agreement with Blanchards' and Gray and McNaughtons' definitions of anxiety, anxiolytic drugs ameliorate acquisition of two-way active - shuttle box-avoidance (by reducing conditioned freezing) essentially during those initial conflicting trials (i.e. when a directed escape response is still not consistently acquired, as freezing is very prominent), but not in more advanced acquisition phases (Figure 1; e.g. [21-24,26, 27,33,35,36]).

To summarize, all the above mentioned studies on the anxiety/fearfulness (i.e. defensive response) profiles of NIH-HS rats have led to the conclusion that the genetically heterogeneous rat stock displays relatively elevated anxiety/fear responses, as shown by unlearned and learned anxiety tests and tasks, while they show interme- diate fear-potentiated startle responses (falling in between the low startle scores of RHA-I-low anxious/ fearful rats and the high startle responses of RLA-Ihigh anxious/fearful rats).

\subsection{Stress Hormone and Depressive-Like Profiles of NIH-HS Rats}

We have also evaluated baseline and stress-induced HPA-axis and prolactin responses in the genetically heterogeneous rat stock, while comparing them with profiles of the low anxious and low stress prone RHA-I and the high anxious, stress prone RLA-I rat strains. The results were reassuring, as for the first time they showed that (1) HPA-axis (i.e. ACTH and corticosterone) responses to stress, which are more marked in RLA-I than RHA-I rats [16,29,37,38], show values which are similar between NIH-HS and RLA-I rats, and (2) baseline and stress-induced prolactin responses (the latter are higher in RLA-I than in RHA-I rats) are more elevated in NIH-HS than even in RLA-I rats [29].

Another cohering finding was that NIH-HS rats show a behavioral "depressive-like" profile in the forced swimming test (i.e. relatively high levels of immobility and low levels of struggling-escape directed behavior), which is closer to that of RLA-I rats than to the profile shown by RHA-I animals in this test $[29,39]$. It is unlikely that the particularly passive coping style of NIH-HS rats in the forced swimming test, as well as in 
the shuttle box avoidance task, can be accounted for by any motor problem or by any general activity deficit, as in separate experiments we have found that NIH-HS rats show higher swimming speed and better efficiency in several learning tasks (in the Morris Water Maze-MWM) than those seen in RHA-I and RLA-I rats. On "escapable" MWM tasks in which rats can leave the pool by finding and climbing into the platform, NIH-HS rats display more motor activity (i.e. higher swimming speed) than both the RHA-I/RLA-I strains (Lopez-Aumatell et al. Paper presented at the 2007 meeting on Rat Genomics \& Models, 6-9 December 2007, Cold Spring Harbor, New York, USA; see also [30]; Martinez-Membrives, unpublished data), thus indicating that the relatively low levels of activity seen in NIH-HS rats are specific of aversive inescapable (i.e. forced swimming test) or highly conflicting situations (i.e. two-way avoidance acquisition) as the ones used in the studies discussed here.

Turning back to the stress hormone findings there is one, however, that we think deserves especial attention: the markedly elevated prolactin levels in NIH-HS rats. It is well known that prolactin works as a mediator between neural and both endocrine and immune systems, with an important involvement in homeostatic regulation when an organism is facing an anxiogenic or stressful situation [40]. Increased stress-induced prolactin responses have been linked to passive coping strategies when facing an aversive situation $[16,38,41,42]$, and this fits well with the fact that the RLA line/strain shows a passive coping style which is paralleled by an exacerbated prolactin response that is not observed in their RHA counterparts [38, 42,43], as it is again confirmed by the above discussed results [29]. Recent microarray results [44] from our group have shown that baseline prolactin gene expression is highly upregulated in the brain of RLA-I compared to RHA-I rats. Moreover, the results of a genetic study by Castanon et al. [41] indicated that two-way avoidance acquisition and prolactin responses to stress were the most important variables to differentiate the Roman rat lines, with the intercorrelations among both variables in segregating crosses suggesting that they could share common genetic regulatory mechanisms [41].

Our results show that NIH-HS rats display predominantly passive/reactive coping responses (as well as stress-induced HPA-axis responses) which resemble the defensive responses shown by the RLA rat line/strain, i.e. high conditioned freezing levels, very poor efficiency to acquire the two-way avoidance response and relatively high levels of immobility (and low levels of struggling) in the forced swimming test. Moreover, our above mentioned study [29] shows for the first time that basal and stress-induced prolactin response of $\mathrm{NIH}-\mathrm{HS}$ rats are markedly elevated, much higher than the values of RHA-I and RLA-I rat strains. It is remarkable, in addition, that factor analysis of NIH-HS results was consistent with the factorial associations reported in the genetic study by Castanon et al. [41], as we also found that poststress prolactin levels are negatively related to the efficiency of two-way avoidance acquisition and positively associated with the levels of context-conditioned freezing/fear (see factor analysis by [29]).

It is worth to point out that WKY (Wistar-Kyoto) rats are among the eight founder strains of the NIH-HS rat stock. In this sense, it is interesting that WKY rats have become one of the best models for depression research ([45-53]; see references in Diaz-Moran et al. [29]), thus showing a predominantly passive coping profile in the forced swimming test, in the hole board, in the open-field test and in the acquisition of two-way active avoidance in the shuttle box, as well as relatively high stress-induced corticosterone and ACTH levels [52,54-60]. Our studies suggest therefore that NIH-HS rats have retained some of the most relevant phenotypic characteristics of the WKY rat strain.

In conclusion, and putting together the previous results and those discussed in Section 2.1, it can be said that the NIH-HS rat stock presents a behavioral/endocrine profile which fits well with one of a rather timid, anxious, passive (reactive) coper and stress-prone "depressive-like" rat.

\subsection{Sex Differences and Hints about Differential Neural Systems Underlying Conditioned Freezing, Startle and Two-Way Avoidance Acquisition}

In the above studies we investigated the pattern of relationships among the different anxiety/fearfulness variables, unlearned and learned, in NIH-HS rats across several tasks. It is worth pointing out that (conditioned) fearpotentiated startle had never been jointly tested for associations with acquisition of two-way avoidance. Thus, we expected that those studies could shed some light on both the possible shared components of unconditioned and conditioned anxiety and on the communalities, if they exist, between classical fear conditioning to a cue (i.e. fear-potentiated startle), context-conditioned fear (freezing) and an instrumental anxiety- and fear-motivated task such as the acquisition of two-way active avoidance (see [21-27,35,36,61,62]). Moreover, the structure of the possible relationships among variables might be an informative starting point with respect to determining, for the first time, the associations among those characters/traits in a genetically heterogeneous rat stock, which in turn might be useful for further (either neurobehavioral or genetic) studies to be carried out with these heterogeneous rats or with other rat strains/stocks.

The observed sex-linked differences in fearfulness are 
mostly in congruence with previous evidence, i.e. females being less anxious or fearful than males as indicated by the majority of variables from both unconditioned and conditioned tests or tasks (e.g. [8,9,12,13,30, 62-64]). The exception to that trend is fear-potentiated startle, in which no sex-related differences appeared (see $[8,13])$. This cannot be considered as an incongruent result, as previous reports with different rat strains have sometimes found either no differences between sexes or even that females appear to be more anxious than males in some conditioned fear tests (e.g. context and cueconditioned freezing; conditioned emotional response paradigm, Vogel's lick suppression test; see [62, 64-66]).

The results of our studies are roughly consistent with previous studies of fearfulness in rodents using multi-test batteries (for review see $[14,61,62]$ ), as refers to the fact that significant across-tests correlations do exist (see as examples [8-13,29,30]) though they are generally modest in magnitude, and especially because factor analyses show a multidimensional structure of anxiety/fear-related behaviors in NIH-HS rats (see below). Thus, as a summary of the main outcome of the factorial analyses from these multitest studies (see, in chronological order, [8,9, $12,13,29]$ ), four relevant conclusions can be drawn:

(i) It has been consistently found that unconditioned/ baseline startle responses are positively associated to (and, according to multiple regression models, predictive of) better acquisition of the anxiety-driven two-way active avoidance task and to lowered conditioned freezing levels $[8-10,13]$. These unexpected but consistent findings will be further discussed below.

(ii) Context-conditioned freezing (i.e. classically conditioned fear) is negatively related to the efficiency to acquire two-way active avoidance [12,13,29,30].

(iii) Unconditioned anxiety responses (e.g. in the ZM and novel-cage tests) are associated with conditioned (learned) anxiety or fear, as shown by loadings of ZM variables and two-way active avoidance variables in the same factor (as can be seen in [8-10,12,13,29]).

(iv) The solution arising in all the factorial studies is a two-fold structure of independent factors. One of the factors is compatible with the concept of "Timidity", usually grouping variables from the unconditioned anxiety tests-see mention to these tests in previous sectionsand shuttle box avoidance measures (these with rather low loadings) (see [8-10,12,13,29]). The other factor would appear to represent "Defensive flight/fear conditioning”, usually including high loadings of two-way avoidance acquisition variables and startle responses (in the studies which included baseline and fear-potentiated startle procedures in the test battery; see [8-10,13]).

Comparison with previous factorial studies using a broad-range of (learned and unlearned) fear/anxiety measures is difficult provided the differences among the tests (e.g. elevated plus-maze and Pavlovian-conditioned freezing in Aguilar et al. [61,62] vs. elevated "zeromaze" and fear-potentiated startle in the present study), and the type of subjects used (F2 rats derived from the Roman strains vs. NIH-HS rats, respectively). Still, as in Aguilar et al.'s study [61], shuttle box avoidance acquisition is also associated to unconditioned measures of fearfulness.

More specifically, and comparing again the defensive profiles of NIH-HS rats and the Roman strains, it is of special interest the fact that extreme scores in "entries into the open sections", "time spent in open sections" (both measures recorded in the ZM test) or "distance/ exploration during the 5-min exposure to a novel cage” predict in a congruent way the levels of conditioned anxiety that NIH-HS rats will show (see also regression analyses in $[8,10])$, as indicated by their efficiency in the acquisition of the two-way shuttle box avoidance task (see $[9-11,13,30])$. This is overall consistent with the profiles of RHA-I (low anxious) and RLA-I (high anxious) rats, as the former show an increased number of entries (and time spent) into the open sections of the ZM test (e.g. [9-11,28,29]; see Table 1(a)), and activity in the 5-min novel-cage test (see $[9,10]$ ), while also showing elevated efficiency in the acquisition of two-way active avoidance (because of their reduced tendency to conditioned freezing, fear; see $[13,28,29])$. Nevertheless, the link between startle responses and shuttle box avoidance acquisition was relatively unexpected, especially because it indicates that the higher the startle responses the better the acquisition of shuttle box avoidance. It must be said, however, that whenever in previous studies the relationships of two-way avoidance acquisition with other conditioned fear tests have been evaluated, they have only been assessed with respect to Pavlovian-conditioned freezing, but not with regard to fear-potentiated startle (see references in $[8,9,61,62]$ ).

Divergences, or even independency, between the neural mechanisms governing those different fear-conditioning-related responses is actually supported by the following findings: (1) septo-hippocampal lesions improve two-way active avoidance, attenuate context-conditioned freezing (for review see [33,34]) and leave fear-potentiated startle unaffected (e.g. [67-69]); (2) basolateral and central amygdala lesions or inactivation (by injection of NMDA [ $N$-methyl-d-aspartate] antagonists) impair acquisition of two-way shuttle box avoidance and of fear-potentiated startle [70-72]. It has been reported that such disruptions of amygdala function impair shuttle box avoidance acquisition by deteriorating the directionality of escape responses and the attentional reactions to the conditioned stimulus (i.e. to the fear cue [70]). But the treatment does not affect contextual fear as measured by freezing responses to the context during the inter-trial 
intervals of shuttle box training [70]. The above-mentioned evidence does not preclude, however, that when the conditioned fear/freezing involved in the initial "active avoidance/passive avoidance" conflict (at shuttle box acquisition) begins to fade, in parallel with the establishment of directed and consistent escape responses, then the amygdala-mediated cue-conditioned startle (i.e. fear-potentiated startle) can play a facilitating role in the animal's responses to the cue (conditioned stimulus; see also [70]). Therefore, our findings suggest that startle responses and acquisition of two-way active avoidance, especially in its very initial stages, could be (at least partly) under different neural control.

When there is a conflict between response tendencies, as in the initial acquisition of two-way active avoidance, the animals have to switch very quickly between fearrelated and anxiety-related behaviors (e.g. fleeing vs. freezing; active avoidance vs. passive avoidance), and the neural mechanisms operating in the resolution of such a conflict seem to preferentially involve control from the septo-hippocampal system $[33,34]$ and the posterior cingulate, although activation of the amygdala is also needed in such phases in order to keep enough autonomic arousal along the process. According to this view, the cue (fear)-elicited fleeing response (i.e. escape to the opposite compartment of the shuttle box, which appears when the initial conflict begins to be overcome) would rather be controlled by the amygdala (e.g. [33,34,67,70, 73]), and, thus, the positive association between shuttle box active responding and acoustic startle should then become clearer as the two-way avoidance acquisition session advances. As a matter of fact, this appears to be the case in our studies $[8,9,13]$ with NIH-HS rats.

Besides the differential involvement of the abovementioned septo-hippocampal and amygdala circuitry in the acquisition of two-way active avoidance and fearpotentiated startle, several reports also point to a divergent involvement of the dopaminergic meso-corticolimbic circuitry (the so-called "motive circuit") in those paradigms (e.g. [74-78]).

To sum up, our studies in NIH-HS rats have shown new behavioral evidence of some expected relationships between unlearned anxiety (i.e. ZM test) and learned fear/anxiety (i.e. two-way active avoidance acquisition), as well as some unexpected links between startle responses and acquisition of two-way shuttle box avoidance. The latter are consistent, howewer, with findings suggesting that startle responses (both baseline and fearpotentiated) are modulated by neural (and possibly genetic, see [25,33]) mechanisms which are at least partly different from those regulating conflict-driven responses, such as the acquisition of the two-way active avoidance task. Anxiety or fearfulness, as measured in laboratory rodents, are not unitary nor simple processes, but complex traits involving different subtypes of behavioral/psychological dimensions which in turn are likely to involve (at least partly) different neurobehavioral and genetic mechanisms.

\section{HETEROGENEOUS NIH-HS RATS AS A TOOL TO DISENTANGLE THE GENETICS OF ANXIETY AND OTHER COMPLEX TRAITS}

Genetic mapping of psychological traits or psychiatric disorders has shown to be harder than initially envisaged. Low heritability, poor characterization of phenotypes, complex "genotype $\times$ phenotype" interactions and the probable polygenic heritability are factors that make the molecular dissection of the above-mentioned traits a demanding challenge. Conversely, genetic mapping of behavioural variation in laboratory animals has led to robust evidence of genetic linkage, as evidenced by many reports of significant association among a variety of behavioural phenotypes and a wide range of chromosomal regions (for review see for example $[79,80]$ ). Moreover, and again in contrast to human studies, replication of genetic mapping findings (linked to different phenotypes) in rodents has been frequent.

One important limitation in the use of animal models has been, thus far, the need to identify and fine map the genetic loci with enough resolution as to allow the identification of the relevant molecular variants. Actually, the identification of molecular variants contributing to strain differences (behavioural variations), has shown to be a difficult task. The main problem stems from the fact that the majority of the available mapping techniques have a poor resolution. Essentially this is because the proportion of variance explained by a single locus is rather smallin most cases less than $10 \%$, even when the total genetic contribution to a trait variation is large. Thus, using an affordable number of animals in a regular laboratory to perform an inbred cross design (commonly, less than 1000 animals), where two inbred rat strains are crossed to obtain a F2 generation [70,81], it is possible to map genetic effects within the order of $5 \%-15 \%$ in intervals that can reach, approximately, half a chromosome. Mapping experiments to resolution levels allowing molecular characterization of quantitative genes would need, nevertheless, more than ten thousand animals [79,81]. Even so, despite its poor resolution, the identification of QTL in F2 animals (i.e. using the above mentioned inbred cross design) has been useful as a strategy to locate genetic influences in particular chromosomes, and so to allow further studies focused to the fine mapping of these chromosomal intervals or QTL. This was the case of a previous work from our group [25], in which for the first time we identified several QTL influencing anxiety/ 
fear-related behaviours in rats (F2 generation derived from crossing the RHA-I and RLA-I rat strains), with a very significant pleiotropic QTL in chromosome 5 . This study was a first and necessary step to allow the later high-resolution fine mapping of QTL in that chromosome, as will be explained below.

The first clue to solve the problem of low resolution of QTL mapping studies came with the work from R. Mott and J. Flint group [81-84], who demonstrated that genetically heterogeneous (outbred) mouse stocks (derived from crossing eight inbred parental strains) allowed the simultaneous detection and fine mapping of QTL and even quantitative gene identification [84]. Genetically heterogeneous stocks of rats (or mice) represent a unique, genetically random mosaic of founding animal chromosomes due to recombinants that have accumulated over many generations. Specifically, the NIH-HS rat stock has been bred for more than 50 generations using a rotational outbreeding regime to minimize the extent of inbreeding, drift and fixation $[1,85]$. At each generation of breeding, there is the potential of new recombinants that could help reduce the size of a QTL (see [86]). Actually, after so many generations it is estimated that the average distance between recombinations enables the fine mapping of QTL into subcentimorgan intervals [81]. This estimation is based on the successful methodology followed by Valdar and colleagues [83], who fine-mapped 843 QTLs for over 100 complex phenotypes/traits in heterogeneous stock mice [81-83,87]. The particularly high genetic recombination of HS mice enabled QTL analysis to such a high resolution level that these QTLs represent chromosomal intervals of $<3 \mathrm{Mb}$, thus even allowing gene identification [81,83,84].

Taking the HS mice work as starting-point, in collaboration with J. Flint's group (Oxford), our group got a colony of 40 breeding matting pairs of genetically heterogeneous NIH-HS rats in 2004 (gently provided by Prof. Eva Redei, Center for Comparative Medicine, Nothwestern University, Chicago, USA), and we carried out the first genetic work (i.e. QTL fine mapping) with the $\mathrm{NIH}-\mathrm{HS}$ rats that proved their potential to identify and to fine-map QTLs. Thus, we reported the analysis of chromosomes 5 and 15 in over 800 NHS-HS rats. At least one QTL, for the "two-way active avoidance" (anxietyrelated) phenotype, was identified and fine-mapped in chromosome 5 (coincident with the QTL found in the original study using the inbred cross design; see [25,86]). That QTL contains nine genes, none of which had been previously shown to influence anxiety-related behaviour $[9,86]$. As said above, that work was confined to the analysis of two chromosomes (5 and 15). However, they were representative of the genetic structure of other chromosomes because the available genotypes from the progenitors of the NIH-HS rat stock indicated that there are no large (>2 Mb) regions without SNPs ("single nucleotide polymorphisms”). After that initial work, we had reasons to believe that the NIH-HS rat stock can be used for whole-genome association studies [86].

As a matter of fact, besides the above mentioned pioneer study by Johannesson et al. [86], identifying and fine mapping a QTL for anxiety in the NIH-HS rat stock, these rats have been successfully used to fine-map QTLs for diabetes-related traits $[88,89]$, and they have been proposed as a new useful model to study the genetics of renal phenotypes [90]. Likewise, the NIH-HS rat stock appears to constitute a unique model for the genomewide simultaneous identification and fine mapping of multiple QTL and quantitative genes underlying bone fragility phenotypes ([91]; Alam et al.'s poster presented at the 2012 ASBMR annual meeting, Minneapolis, Minnesota, USA), autoimmune encephalomyelitis (a model of multiple sclerosis; e.g. [30,92]), other neuroinflammatory phenotypes, cardiovascular and several other biological and/or disease-related phenotypes or traits (e.g. $[30,86,92]$; Tuncel et al. submitted). Progress in all these areas, i.e. genome-wide fine mapping of QTLs for many (behavioural, physiological/biological disease-related) complex traits-including anxiety/fear phenotypes and quantitative gene identification, is currently under way within the context of the EURATRANS European consortium and, hopefully, will led to outstanding new reports and important results shortly (several of these papers have been submitted for publication and are currently under evaluation, e.g. Tuncel et al. submitted; see also [30,86,92]).

As mentioned earlier, the NIH-HS rats show a unique feature: genetic recombinants (derived from the 8 founder inbred strains) accumulated over many generations of outbreeding. This model is also favourable in economical terms, since each single animal can provide a considerable amount of information on multiple phenotypes/traits (see $[30,86])$. The wealth of phenotypic and genotypic information can be later combined with gene expression data, to provide the basis for a systems biology approach to the understanding of how complex phenotypes arise from the resulting complex multidirectional net of genes and environment [93,94].

In this connection, our group has initiated a series of microarray studies devoted to investigate gene expression in the amygdala and hippocampus of NIH-HS rats displaying extremely high or low anxiety/fearfulness phenotypes. Over 400 differentially-expressed genes, i.e. in "Low anxious" vs. "High anxious" NIH-HS rats, were detected in amygdala, of which $>30$ genes were related with neurobiological, endocrine, immunological or neurobehavioural functions/processes (see [28,95]). Remarkably, some of the most clearly different genes from the amygdala of "Low anxious" vs. "High anxious" rats 
are involved in HPA-axis and stress/anxiety regulation, in vassopresinergic function or in prolactin pathways (e.g. $[28,95])$, this being to some extent in line with findings from a study with the (low anxious) RHA-I and (high anxious) RLA-I rat strains, which showed differential expression of HPA-axis and prolactin related genes [44]. We have also found over 200 differentially-expressed genes in the hippocampus of "Low anxious" vs. "High anxious" NIH-HS rats, of which $>60$ genes are involved in neurobiological, endocrine, immunological or behavioural functions/processes [28]. Importantly, some of these genes are related with hypothalamic hormone regulation and stress responses, galanin and vassopresin systems, as well as with the cholinergic system [28].

It is to be expected that, taking advantage of the unique value of the NIH-HS rat for genetic studies of complex phenotypes, integration among the definitive gene expression results and fine-mapped QTLs will lead to relevant insights on novel gene-physiological pathways for the traits under investigation.

\section{CONCLUSIONS AND PERSPECTIVES}

We have demonstrated that the NIH-HS rat colony (at Autonomous University of Barcelona) exhibits a behavioural "defensive" profile indicating that these animals are rather fearful and anxious, presenting a predominantly passive/reactive coping style as well as a "depressive” and stress-prone hormone profile. Thus, the anxiety/fear and stress hormone profiles of NIH-HS rats are much closer to the (high anxious, stress-prone) passive coper RLA-I rats than to the (low anxious, stress resistant) proactive coper RHA-I rats.

The use of multiple anxiety and fear (conditioned and unconditioned) tests and tasks, to characterize these traits in NIH-HS rats, enabled us to find associations among different types of defensive responses that have not been reported before, which led to novel factorial/dimensional structures. In particular, we have observed that baseline and/or fear-potentiated startle (depending on the gender) are "positive" predictors of efficiency in the acquisition of two-way active avoidance, which points to a differential neural (and possibly genetic) regulation of both fearrelated responses.

Due to the large amount of recombinants (and many generations of outbreeding) accumulated, the NIH-HS rats enable high resolution QTL mapping. Actually, we and others have demonstrated that fine-mapping of QTLs for complex traits, to a resolution level even enabling candidate gene identification, is possible in NIH-HS rats (for instance see Johannesson et al. [86] for QTL for anxiety traits, and Solberg et al. [89,90], for diabetesrelated phenotypes). These results establish the NIH-HS rat stock as a unique genetic resource for fine mapping of QTL for complex traits [86,89-91].
A current major challenge in biology in general (and in neurobiology in particular) is to understand how phenotypes arise from gene-physiology (environment) networks and interactions [93,94,96,97]. Critical to this endeavour is the collection of sufficiently dense data sets, integrating data from QTL mapping, genetic variants and gene transcription to identify networks. Such a combined strategy is being applied to a very large study, which has used an extensive high-throughput phenotyping strategy (for details see [86]) in over 1400 NIH-HS rats. Over 100 phenotypes have been measured, including behavioural (anxiety- and fearfulness-related) traits, common disease-related traits, biochemistry, haematology and immunology-related traits. It is expected that this combined approach using the heterogeneous NIH-HS rats stock will provide a significant international resource for systems biology applications [30,86,92] and, in particular, we expect that type of research will shed light on the genetic-physiological network mechanisms involved in fearfulness, anxiety and related traits.

\section{ACKNOWLEDGEMENTS}

Supported by grants for the MICINN (PSI2009-10532), “Fundació La Maratò TV3” (ref. 092630/31), 2009SGR-0051 and the European project/consortium “EURATRANS” (grant agreement HEALTH-F42010-241504). C.M.-C. is recipient of a FPI (2010; MICINN) Ph.D. fellowship and C.E. was recipient of a postdoctoral fellowship from CNPq (201456/2011-7). Thanks also to Jaume F. Lalanza for their psychometric and methodological advice.

\section{REFERENCES}

[1] Hansen, C. and Spuhler, K. (1984) Development of the National Institutes of Health genetically heterogeneous stock. Alcoholism: Clinical and Experimental Research, 8, 477-479. doi:10.1111/j.1530-0277.1984.tb05706.x

[2] Spuhler, K. and Dietrich, R.A. (1984) Correlative analysis of ethanol-related phenotypes in rat inbred strains. Alcoholism: Clinical and Experimental Research, 8, 480484. doi:10.1111/j.1530-0277.1984.tb05707.x

[3] Draski, L.J., Spuhler, K.P., Erwin, V.G., Baker, R.C. and Dietrich, R.A. (1992) Selective breeding of rats differing in sensitivity to the effects of acute ethanol administration. Alcoholism: Clinical and Experimental Research, 16, 4854. doi:10.1111/j.1530-0277.1992.tb00634.x

[4] Koch, L.G. and Britton, S.L. (2001) Artificial selection for intrinsic aerobic endurance running capacity in rats. Physiological Genomics, 5, 45-52.

[5] Troxell, M.L., Loyal Britton, S. and Koch, L.G. (2003) Genetic models in applied physiology: Selected contribution: Variation and heritability for the adaptational response to exercise in genetically heterogeneous rats. Journal of Applied Physiology, 94, 1674-1681.

[6] Overstreet, D.H., Rezvani, A.H., Pucilowski, O., Gause, L. and Janowsky, D.S. (1994) Rapid selection for sero- 
tonin-1A sensitivity in rats. Psychiatric Genetics, 4, 5762. doi:10.1097/00041444-199421000-00008

[7] Aitman, T.J., Critser, J.K., Cuppen, E., Dominiczak, A., Fernandez-Suarez, X.M., Flint, J., Gauguier, D., Geurts, A.M., Gould, M., Harris, P.C., Holmdahl, R., Hubner, N., Izsvák, Z., Jacob, H.J., Kuramoto, T., Kwitek, A.E., Marrone, A., Mashimo, T., Moreno, C., Mullins, J., Mullins, L., Olsson, T., Pravenec, M., Riley, L., Saar, K., Serikawa, T., Shull, J.D., Szpirer, C., Twigger, S.N., Voigt, B. and Worley, K. (2008) Progress and prospects in rat genetics: A community view. Nature Genetics, 40, 516-522. doi:10.1038/ng.147

[8] López-Aumatell, R., Guitart-Masip, M., Vicens-Costa, E., Gimenez-Llort, L., Valdar, W., Johannesson, M., et al. (2008) Fearfulness in a large N/NIH genetically heterogeneous rat stock: Differential profiles of timidity and defensive flight in males and females. Behavioural Brain Research, 188, 41-55. doi:10.1016/j.bbr.2007.10.015

[9] López-Aumatell, R. (2008) Temerositat en rates heterogènies N/NIH-HS: Vers els gens quantitatius de l'ansietat i la por. Ph.D. Thesis, Autonomous University of Barcelona, Barcelona.

[10] López-Aumatell, R., Vicens-Costa, E., Guitart-Masip, Martínez-Membrives, M., Valdar, W., Johannesson, M., Cañete, T., Blázquez, G., Driscoll, P., Flint, J., Tobeña, A. and Fernández-Teruel, A. (2009) Unlearned anxiety predicts learned fear: A comparison among heterogeneous rats and the Roman rat strains. Behavioural Brain Research, 202, 92-101. doi:10.1016/j.bbr.2009.03.024

[11] López-Aumatell, R., Vicens-Costa, E., Guitart-Masip, M., Martínez-Membrives, E., Valdar, W., Johannesson, M., Cañete, T., Blázquez, G., Giménez-Llort, L., Flint, J., Tobeña, A. and Fernández-Teruel, A. (2009) Ansiedad en ratas genéticamente heterogéneas: Hacia la identificación de genes para caracteres conductuales cuantitativos. Ansiedad y Estrés, 15, 67-84.

[12] López-Aumatell, R., Martínez-Membrives, E., VicensCosta, E., Cañete, T., Blázquez, G., Mont-Cardona, C., Johannesson, M., Flint, J, Tobeña, A. and FernándezTeruel, A. (2011) Effects of environmental and physiological covariates on sex differences in unconditioned and conditioned anxiety and fear in a large sample of genetically heterogeneous (N/NIH-HS) rats. Behavioral and Brain Functions, 7, 48. doi:10.1186/1744-9081-7-48

[13] Vicens-Costa, E., Martínez-Membrives, E., López-Aumatell, R., Guitart-Masip, M., Cañete, T., Blázquez, G., Tobeña, A. and Fernández-Teruel, A. (2011) Two-way avoidance acquisition is negatively related to conditioned freezing and positively associated with startle reactions: A dissection of anxiety and fear in genetically heterogeneous rats. Physiology \& Behavior, 103, 148-156. doi:10.1016/j.physbeh.2010.12.009

[14] Ramos, A. and Mormede, P. (1998) Stress and emotionality: A multidimensional and genetic approach. Neuroscience \& Biobehavioral Reviews, 22, 33-57. doi:10.1016/S0149-7634(97)00001-8

[15] Shepherd, J.K., Grewal, S.S., Fletcher, A., Bill, D.J. and Dourish, C.T. (1994) Behavioural and pharmacological characterisation of the elevated "zero-maze" as an animal model of anxiety. Psychopharmacology, 116, 56-64.

\section{doi:10.1007/BF02244871}

[16] Steimer, T. and Driscoll, P. (2003) Divergent stress responses and coping styles in psychogenetically selected Roman high-(RHA) and low-(RLA) avoidance rats: Behavioural, neuroendocrine and developmental aspects. Stress, 6, 87-100. doi:10.1080/1025389031000111320

[17] Aguilar, R., Gil, L., Tobeña, A., Escorihuela, R.M. and Fernández-Teruel, A. (2000) Differential effects of cohort removal stress on the acoustic startle response of the Roman/Verh rat strains. Behavior Genetics, 30, 71-75. doi:10.1023/A:1002042711672

[18] Schwegler, H., Pilz, P.K.D., Koch, M., Fendt, M., Linke, R. and Driscoll, P. (1997) The acoustic startle response in inbred Roman high- and low-avoidance rats. Behavior Genetics, 27, 579-582. doi:10.1023/A:1021465217299

[19] Davis, M., Falls, W.A., Campeau, S. and Kim, M. (1993) Fear-potentiated startle: A neural and pharmacological analysis. Behavioural Brain Research, 58, 175-198. doi:10.1016/0166-4328(93)90102-V

[20] López-Aumatell, R., Blázquez, G., Gil, L., Aguilar, R., Cañete, T., Giménez-Llort, L., Tobeña, A. and Fernández-Teruel, A. (2009) The Roman high-and low-avoidance rat strains differ in fear-potentiated startle and classical aversive conditioning. Psicothema, 21, 27-32.

[21] Escorihuela, R.M., Fernández-Teruel, A., Zapata, A., Nuñez, J.F. and Tobeña, A. (1993) Flumazenil prevents the anxiolytic effects diazepam, alprazolam and adinazolam on the early acquisition of two-way active avoidance. Pharmacological Research, 28, 53-58. doi:10.1006/phrs.1993.1109

[22] Fernández-Teruel, A., Escorihuela, R.M., Boix, F. and Tobeña, A. (1991) Effects of different handling-stimulation procedures and benzodiazepines on two-way active avoidance acquisition in rats. Pharmacological Research, 24, 273-282. doi:10.1016/1043-6618(91)90091-B

[23] Fernández-Teruel, A., Escorihuela, R.M., Nuñez, J.F., Zapata, A., Boix, F., Salazar, W. and Tobeña, A. (1991) The early acquisition of two-way (shuttle-box) avoidance as an anxiety-mediated behaviour: Psychopharmacological validation. Brain Research Bulletin, 26, 173-176. doi:10.1016/0361-9230(91)90205-X

[24] Fernández-Teruel, A., Escorihuela, R.M., Tobeña, A. and Driscoll, P. (1991) Stress and putative endogenous ligands for benzodiazepine receptors: The importance of characteristics of the aversive situation and of differential emotionality in experimental animals. Experientia, 47, 1051-1056. doi:10.1007/BF01923340

[25] Fernández-Teruel, A., Escorihuela, R.M., Gray, J.A., Aguilar, R., Gil, L., Giménez-Llort, L., Tobeña, A., Bhomra, A., Nicod, A., Mott, R., Driscoll, P., Dawson, GR. and Flint, J. (2002) A quantitative trait locus influencing anxiety in the laboratory rat. Genome Research, 12, 618-626.

[26] Prunell, M., Escorihuela, R.M., Fernández-Teruel, A., Nuñez, J.F. and Tobeña, A. (1994) Differential interactions between ethanol and Ro 15-4513 on two anxiety tests in rats. Pharmacology Biochemistry and Behavior, 47, 147-151. doi:10.1016/0091-3057(94)90124-4

[27] Prunell, M., Escorihuela, R.M., Fernández-Teruel, A., Nuñez, J.F. and Tobeña, A. (1994) Anxiolytic profiles of 
alprazolam and ethanol in the elevated plus-maze test and the early acquisition of shuttlebox avoidance. Pharmacological Research, 29, 37-45. doi:10.1016/1043-6618(94)80096-0

[28] Díaz-Morán, S. (2012) Temerosidad en ratas heterogéneas (N/NIH-HS) y Romanas (RHA/RLA): Estudios hormonales y de expresión génica diferencial. Ph.D. Thesis, Autonomous University of Barcelona, Barcelona.

[29] Díaz-Morán, S., Mont-Cardona, C., Cañete, T., Blázquez, G., Martínez-Membrives, E., López-Aumatell, R., Tobeña, A. and Fernández-Teruel, A. (2012) Coping style and stress hormone responses in genetically heterogeneous rats: Comparison with the Roman rat strains. Behavioural Brain Research, 228, 203-210. doi:10.1016/j.bbr.2011.12.002

[30] Martinez-Membrives, E. (2012) Susceptibility to experimental autoimmune encephalomyelitis (model of multiple sclerosis) and anxiety in heterogeneous rats. Ph.D. Thesis, Autonomous University of Barcelona, Barcelona.

[31] Blanchard, R.J., Blanchard, D.C., Rodgers, J. and Weiss, S.M. (1990) The characterization and modeling of antipredator defensive behavior. Neuroscience \& Biobehavioral Reviews, 14, 463-472. doi:10.1016/S0149-7634(05)80069-7

[32] Blanchard, R.J., Yudko, E.B., Rodgers, J. and Blanchard, D.C. (1993) Defense system psychopharmacology: An ethological approach to the pharmacology of fear and anxiety. Behavioural Brain Research, 58, 155-165. doi:10.1016/0166-4328(93)90100-5

[33] Gray, J.A. and McNaughton, N. (2000) The neuropsychology of anxiety: An enquiry into the functions of the septo-hippocampal system. 2nd Edition, Oxford University Press, Oxford.

[34] McNaughton, N. and Gray, J.A. (2000) Anxiolytic action on the behavioural inhibition system implies multiple types of arousal contribute to anxiety. Journal of Affective Disorders, 61, 161-176. doi:10.1016/S0165-0327(00)00344-X

[35] Boix, F., Fernández-Teruel, A. and Tobeña, A. (1988) The anxiolytic action of benzodiazepines is not present in handling-habituated rats. Pharmacology Biochemistry and Behavior, 31, 541-546. doi:10.1016/0091-3057(88)90228-6

[36] Gray, J.A. (1982) The neuropsychology of anxiety: An enquiry into the functions of the septo-hippocampal system. Oxford University Press, Oxford.

[37] Carrasco, J., Márquez, C., Nadal, R., Tobeña, A., Fernández-Teruel, A. and Armario, A. (2008) Characterization of central and peripheral components of the hypothalamus-pituitary-adrenal axis in the inbred Roman rat strains. Psychoneuroendocrinology, 33, 437-445. doi:10.1016/j.psyneuen.2008.01.001

[38] Steimer, T. and Driscoll, P. (2005) Inter-individual vs. line/strain differences in psychogenetically selected Roman high-(RHA) and low-(RLA) avoidance rats: Neuroendocrine and behavioural aspects. Neuroscience \& Biobehavioral Reviews, 29, 99-112. doi:10.1016/j.neubiorev.2004.07.002

[39] Piras, G., Barbato, A., Giorgi, O. and Corda, M. (2010)
Effects of antidepressants on the performance in the forced swim test of two psychogenetically selected lines of rats that differ in coping strategies to aversive condictions. Psychopharmacology (Berlin), 211, 403-414. doi:10.1007/s00213-010-1904-X

[40] Freeman, M.E., Kanyicska, B., Lerant, A. and Nagy, G. (2001) Prolactin: Structure, function and regulation of secretion. Physiological Reviews, 80, 1523-1631.

[41] Castanon, N., Pérez-Díaz, F. and Mormede, P. (1995) Genetic analysis of the relationship between behavioral and neuroendocrine traits in Roman high and low avoidance rat lines. Behavior Genetics, 25, 371-383. doi:10.1007/BF02197288

[42] Steimer, T., la Fleur, S. and Schulz, P.E. (1997) Neuroendocrine correlates of emotional reactivity and coping in male rats from the Roman High (RHA/Verh)- and Low (RLA/Verh)-Avoidance lines. Behavior Genetics, 27, 503-512. doi:10.1023/A:1021448713665

[43] Castanon, N., Dulluc, J., Le Moal, M. and Mormêde, P. (1992) Prolactin as a link between behavioral and immune differences between the Roman rat lines. Physiology \& Behavior, 51, 1235-1241. doi:10.1016/0031-9384(92)90314-R

[44] Sabariego, M., Gómez, M.J., Morón, I., Torres, C., Fernández-Teruel, A., Tobeña, A., Cañete, T., MartínezConejero, J.A., Horcajadas, J.A. and Esteban, F.J. (2011) Differential gene expression between inbred Roman high(RHA-I) and low-(RLA-I) avoidance rats. Neuroscience Letters, 504, 265-270. doi:10.1016/j.neulet.2011.09.044

[45] Armario, A., Gabaldá, A. and Martí, J. (1994) Comparison of the behavioural and endocrine response to forced swimming stress in five inbred strains of rats. Psychoneuroendocrinology, 20, 879-890. doi:10.1016/0306-4530(95)00018-6

[46] Braw, Y., Malkesman, O., Dagan, M., Bercovich, A., Lavi-Avnon, Y., Schroeder, M., et al. (2006) Anxietylike behaviours in pre-pubertal rats of the flinders sensitive lines (FSL) and Wistar-Kyoto (WKY) animal models of depression. Behavioural Brain Research, 167, 261-219. doi:10.1016/j.bbr.2005.09.013

[47] Malkesman, O., Braw, Y., Zagoory-Sharon, O., Golan, O., Lavi-Avnon, Y., Schroeder, M., et al. (2005) Reward and anxiety in genetic animal models of childhood depression. Behavioural Brain Research, 164, 1-10. doi:10.1016/j.bbr.2005.04.023

[48] Malkesman, O., Braw, Y., Maayan, R., Weizman, A., Overstreet, D.H., Shabat-Simon, M., et al. (2006) Two different putative genetic animal models of childhood depression. Biological Psychiatry, 59, 17-23. doi:10.1016/j.biopsych.2005.05.039

[49] Paré, W.P. (1989) Behavioral despair test predicts stress ulcer in WKY rats. Physiology \& Behavior, 46, 483-487. doi:10.1016/0031-9384(89)90025-5

[50] Paré, W.P. (1989) Stress ulcer susceptibility and depression in wistar Kyoto (WKY) rats. Physiology \& Behavior, 46, 993-998. doi:10.1016/0031-9384(89)90203-5

[51] Paré, W.P. (1992) The performance of WKY rats on three tests of emotional behaviour. Physiology \& Behavior, 51, 
1051-1056. doi:10.1016/0031-9384(92)90091-F

[52] Paré, W.P. (1994) Open field, learned helplessness, conditioned defensive burying, and forced swim test in WKY rats. Physiology \& Behavior, 55, 433-439. doi:10.1016/0031-9384(94)90097-3

[53] Solberg, L.C., Olson, S.L., Turek, F.W. and Redei, E. (2001) Altered hormone levels and circadian rhythm of activity in the WKY rat, a putative animal model of depression. American Journal of Physiology-Regulatory, Integrative and Comparative Physiology, 281, R786R794.

[54] Athey, G.R. and Iams, S.G. (1981) Cold-restraint induced gastric lesions in normotensive and spontaneously hypertensive rats. Life Science, 28, 889-894. doi:10.1016/0024-3205(81)90050-3

[55] Gomez, F., Lahmame, A., de Kloet, E.R. and Armario, A. (1996) Hypothalamic-pituitary-adrenal response to chronic stress in five inbred rat strains: differential responses are mainly located at the adrenocortical level. Neuroendocrinology, 63, 327-337. doi:10.1159/000126973

[56] Lahmame, A., Grigoriadis, D.E., De Souza, E.B. and Armario, A. (1997) Brain corticotropinreleasing factor immunoreactivity and receptors in five inbred rat strains: Relationship to forced swimming behaviour. Brain Research, 750, 285-292.

doi:10.1016/S0006-8993(96)01368-6

[57] Ledoux, J.E., Sakaguchi, A. and Reis, D.J. (1983) Strain differences in fear between spontaneously hypertensive and normotensive rats. Brain Research, 277, 137-143. doi:10.1016/0006-8993(83)90915-0

[58] Paré, W.P. and Redei, E. (1993) Depressive behaviour and stress ulcer in Wistar-Kyoto rats. Journal of Physiology-Paris, 87, 229-238. doi:10.1016/0928-4257(93)90010-Q

[59] Redei, E., Paré, W.P., Aird, F. and Klucynski, J. (1994) Strain differences in hypothalamic-pituitary-adrenal activity and stress ulcer. American Journal of Physiology, 266, R353-R360.

[60] Servatius, R.J., Ottenweller, J.E., Beldowizc, D., Guo, W., Zhu, G. and Natelson, B.H. (1998) Persistenly exaggerated startle responses in rats treated with pyridostigmine bromide. Journal of Pharmacology and Experimental Therapeutics, 287, 1020-1028.

[61] Aguilar, R., Gil, L., Flint, J., Gray, J.A., Dawson, G.R., Driscoll, P., et al. (2002) Learned fear, emotional reactivity and fear of heights: A factor analytic map from a large F2 intercross of Roman rat strains. Brain Research Bulletin, 57, 17-26. doi:10.1016/S0361-9230(01)00632-3

[62] Aguilar, R., Gil, L., Gray, J.A., Driscoll, P., Flint, J., Dawson, G.R., et al. (2003) Fearfulness and sex in F2 Roman rats: Males display more fear though both sexes share the same fearfulness traits. Physiology \& Behavior, 78, 723-732. doi:10.1016/S0031-9384(03)00043-X

[63] Fernandes, C., González, M.I., Wilson, C. and File, S.E. (1999) Factor analysis shows that female rat behavior is characterized primarily by activity, male rats are driven by sex and anxiety. Pharmacology Biochemistry and Behavior, 64, 731-738.

doi:10.1016/S0091-3057(99)00139-2
[64] Lehmann, J., Pryce, C.R. and Feldon, J. (1999) Sex differences in the acoustic startle response and prepulse inhibition in Wistar rats. Behavioural Brain Research, 104, 113-117. doi:10.1016/S0166-4328(99)00058-3

[65] Brush, F.R., Del Paine, S.L., Pellegrino, L.J., Rykazewwski, I.M., Dess, N.K. and Collins, P. (1988) CER suppression, passive-avoidance learning, and stress-suppression of drinking in the Siracuse high- and low-avoidance strains of rats (Rattus norvegicus). Journal of Comparative Psychology, 102, 337-339. doi:10.1037/0735-7036.102.4.337

[66] Johnston, A.L. and File, S.E. (1991) Sex differences in animal tests of anxiety. Physiology \& Behavior, 49, 245250. doi:10.1016/0031-9384(91)90039-Q

[67] McNish, K.A., Gewirtz, J.C. and Davis, M. (1997) Evidence of contextual fear after lesions of the hippocampus: A disruption of freezing but not fear-potentiated startle. Journal of Neuroscience, 17, 9353-9260.

[68] Phillips, R.G. and LeDoux, J.E. (1992) Differential contribution of amygdala and hippocampus to cued and contextual fear conditioning. Behavioral Neuroscience, 106, 274-285. doi:10.1037/0735-7044.106.2.274

[69] Phillips, R.G. and LeDoux, J.E. (1994) Lesions of the dorsal hippocampal formation interfere with background but no foreground contextual fear conditioning. Learning \& Memory, 1, 34-44.

[70] Savonenko, A., Werka, T., Nikolaev, E., Zielinski, K. and Kaczmarek, L. (2003) Complex effects of NMDA recaptor antagonist AVP in the basolateral amygdala on acquisition of two-way avoidance reaction and long-term fear memory. Learning \& Memory, 10, 293-303. doi:10.1101/lm.58803

[71] Werka, T. (1997) The effects of the medial and cortical amygdala lesions on poststress analgesia in rats. Behavioural Brain Research, 86, 59-65. doi:10.1016/S0166-4328(96)02244-9

[72] Werka, T. and Zielinski, K. (1998) CS modality transfer of two-way avoidance in rats with central and basolateral amygdala lesions. Behavioural Brain Research, 93, 11-24. doi:10.1016/S0166-4328(97)00131-9

[73] Davis, M., Falls, W.A., Campeau, S. and Kim, M. (1993) Fear-potentiated startle: A neural and pharmacological analysis. Behavioural Brain Research, 58, 175-198. doi:10.1016/0166-4328(93)90102-V

[74] Josselyn, S.A., Falls, W.A., Gewirtz, J.C., Pistell, P. and Davis, M. (2005) The nucleus accumbens is not critically involved in mediating the effects of a safety signal on behavior. Neuropsychopharmacology, 30, 17-26. doi:10.1038/sj.npp.1300530

[75] Oliveira, A.R., Reimer, A.E. and Brandao, M.L. (2006) Dopamine D2 receptor mechanisms in the expression of conditioned fear. Pharmacology Biochemistry and Behavior, 84, 102-111. doi:10.1016/j.pbb.2006.04.012

[76] Reis, F.L.V., Masson, S., Oliveira, A.R. and Brandao, M.L. (2004) Dopaminergic mechanisms in the conditioned and unconditioned fear as assessed by the two-way avoidance and switch-off tests. Pharmacology Biochemistry and Behavior, 79, 359-365. doi:10.1016/j.pbb.2004.08.006 
[77] Schultz, W. (2002) Getting formal with dopamine and reward. Neuron, 36, 241-263. doi:10.1016/S0896-6273(02)00967-4

[78] Stark, H., Rothe, T., Wagner, T. and Scheich, H. (2004) Learning a new behavioral strategy in the shuttle-box increases prefrontal dopamine. Neuroscience, 126, 21-29. doi:10.1016/j.neuroscience.2004.02.026

[79] Flint, J. and Mott, R. (2001) Finding the molecular basis of quantitative traits: successes and pitfalls. Nature Reviews Genetics, 2, 437-445. doi:10.1038/35076585

[80] Kwitek-Black, A.E. and Jacob, H.J. (2001) The use of designer rats in the genetic dissection of hypertension. Current Hypertension Reports, 3, 12-18. doi:10.1007/s11906-001-0072-0

[81] Mott. R., Talbot, C.J., Turri, M.G., Collins, A.C. and Flint, J. (2000) A method for fine mapping quantitative trait loci in outbred animal stocks. Proceedings of the National Academy of Sciences of the United States of America, 97, 12649-12654. doi:10.1073/pnas.230304397

[82] Mott, R. and Flint, J. (2002) Simultaneous detection and fine mapping of quantitative trait loci in mice using heterogeneous stocks. Genetics, 160, 1609-1618.

[83] Valdar, W., Solberg, L.C., Gauguier, D., Burnett, S., Klenerman, P., Cookson, W.O., Taylor, M.S., Rawlins, J.N., Mott, R. and Flint, J. (2006) Genome-wide genetic association of complex traits in heterogeneous stock mice. Nature Genetics, 38, 879-887. doi:10.1038/ng1840

[84] Yalcin, B., Willis-Owen, S.A., Fullerton, J., Meesaq, A., Deacon, R.M., Rawlins, J.N., Copley, R.R., Morris, A.P., Flint, J. and Mott, R. (2004) Genetic dissection of a behavioral quantitative trait locus shows that Rgs2 modulates anxiety in mice. Nature Genetics, 36, 1197-1202. doi:10.1038/ng1450

[85] Boucher, W. and Cotterman, C.W. (1990) On the classification of regular systems of inbreeding. Journal of Mathematical Biology, 28, 293-305. doi:10.1007/BF00178778

[86] Johannesson, M., López-Aumatell, R., Stridh, P., Diez, M., Tuncel, J., Blázquez, G., Martinez-Membrives, E., Cañete, T., Vicens-Costa, E., Graham, D., Copley, R.R., Hernandez-Pliego, P., Beyeen, A.D., Ockinger, J., Fernández-Santamaría, C., Gulko, P.S., Brenner, M., Tobeña, A., Guitart-Masip, M., Giménez-Llort, L., Dominiczak, A., Holmdahl, R., Gauguier, D., Olsson, T., Mott, R., Valdar, W., Redei, E.E., Fernández-Teruel, A. and Flint, J. (2009) A resource for the simultaneous high-resolution mapping of multiple quantitative trait loci in rats: The NIH heterogeneous stock. Genome Research, 19, 150158. doi:10.1101/gr.081497.108

[87] Flint, J. (2004) The genetic basis of neuroticism. Neuroscience \& Biobehavioral Reviews, 28, 307-316. doi:10.1016/j.neubiorev.2004.01.004

[88] Solberg Woods, L.C., Stelloh, C., Regner, K.R., Schwabe, T., Eisenhauer, J. and Garrett, M.R. (2010) Heterogeneous stock rats: A new model to study the genetics of renal phenotypes. American Journal of Physiology-Renal Physiology, 298, 1484-1491. doi:10.1152/ajprenal.00002.2010

[89] Solberg Woods, L.C., Holl, K.L., Oreper, D., Xie, Y., Tsaih, S.W. and Valdar, W. (2012) Fine-mapping diabetes-related traits, including insulin resistance, in heterogeneous stock rats. Physiological Genomics, 44, 10131026. doi:10.1152/physiolgenomics.00040.2012

[90] Solberg Woods, L.C., Holl, K., Tschannen, M. and Valdar, W. (2010) Fine-mapping a locus for glucose tolerance using heterogeneous stock rats. Physiological Genomics, 41, 102-108. doi:10.1152/physiolgenomics.00178.2009

[91] Alam, I., Koller, D.L., Sun, Q., Roeder, R.K., Cañete, T., Blázquez, G., López-Aumatell, R., Martínez-Membrives, E., Vicens-Costa, E., Mont, C., Díaz, S., Tobeña, A., Fernández-Teruel, A., Whitley, A., Strid, P., Diez, M., Johannesson, M., Flint, J., Econs, M.J., Turner, C.H. and Foroud, T. (2011) Heterogeneous stock rat: A unique animal model for mapping genes influencing bone fragility. Bone, 48, 1169-1177. doi:10.1016/j.bone.2011.02.009

[92] Stridh, P. (2010) Inheritance of autoimmune neuroinflammation. Ph.D. Thesis, Karolinska Institutet, Stockholm.

[93] Barabási, A.L. and Oltvai, Z.N. (2004) Network biology: Understanding the cell's functional organization. Nature Reviews Genetics, 5, 101-113. doi:10.1038/nrg1272

[94] Hartwell, L.H., Hopfield, J.J., Leibler, S. and Murray, A.W. (1999) From molecular to modular cell biology. Nature, 402, C47-C52. doi:10.1038/35011540

[95] Díaz-Morán, S., Palència, M., Cañete, T., Blázquez, G., Morón, I., Sabariego, M., Donaire, R., Torres, C., MontCardona, C., Martínez-Membrives, E., López-Aumatell, R., Martínez-Conejero, J.A., Tobeña, A. and FernándezTeruel, A. (2012) Aplicabilidad del análisis de microarray en la detección de patrones de expresión genética diferencial en procesos psicológicos: Expresión genética amigdalar en ratas N/NIH-HS extremas en ansiedad. Iniciación a la investigación, 6, 1-8.

[96] Huang, G., Shifman, S., Valdar, W., Johannesson, M., Yalcin, B., Taylor, M.S., Taylor, J.M., Mott, R. and Flint, J. (2009) High resolution mapping of expression QTLs in heterogeneous stock mice in multiple tissues. Genome Research, 19, 1133-1140. doi:10.1101/gr.088120.108

[97] Flint, J. and Eskin, E. (2012) Genome-wide association studies in mice. Nature Reviews Genetics, 13, 807-816. doi:10.1038/nrg3335 